\title{
Alteration of ERß gene Rsal polymorphism may contribute to reduced fertilization rate and embryonic developmental competence
}

\begin{abstract}
Qiu-Fang Zhang ${ }^{1}$, Huai-Liang Feng ${ }^{2}$, Lan Zhao ${ }^{1}$, Ping Liu ${ }^{1}, \mathrm{Li} \mathrm{Li}^{1}$, Jie Yan $^{1}$ and Jie Qiao ${ }^{1}$
This paper aims to determine the possible role of estrogen receptor- $\beta$ (ER $\beta)$ gene Rsal polymorphism on sperm fertility and early embryonic development in humans. Three groups of Chinese men were recruited: in vitro fertilization (IVF) group, including 374 couples who underwent conventional IVF; intracytoplasmic sperm injection (ICSI) group, including 294 couples who underwent an ICSI procedure using ejaculated sperm; and azoospermic group, consisting of 197 couples who underwent ICSI using either testis or epididymis sperm. Rsal polymorphism in the ERß gene was detected by polymerase chain reaction (PCR)-restriction fragment length polymorphism technique; fertilization and high-quality embryo rates were evaluated for each group. In each group, no significant differences were found in the overall rates of fertilization and high-quality embryos among GG, AG and AA genotypes. However, the proportion of cycles possessing a satisfactory high-quality embryo rate with the AA genotype was significantly lower than that in the wild-type GG genotype from each group. These results demonstrated that sperm possessing the ERß Rsal A genotype may have reduced fertilization ability and decreased early embryonic developmental potential, which could directly or indirectly contribute to the low fertilization rate and early embryonic developmental arrest in some cases.
\end{abstract}

Asian Journal of Andrology (2011) 13, 317-321; doi:10.1038/aja.2010.150; published online 6 December 2010

Keywords: embryo development; estrogen receptor- $\beta$ gene; fertilization; intracytoplasmic sperm injection; in vitro fertilization; polymorphism

\section{INTRODUCTION}

There is much evidence to suggest that estrogen and estrogen receptors (ERs) play very important roles during male reproduction. ${ }^{1-5}$ In the male testes, estrogens are synthesized from testosterone via the action of aromatase cytochrome P450. Some studies have shown that aromatase deficiencies cause progressive infertility in adult mice, resulting in reduced sperm production and motility. ${ }^{6-8}$ However, although many studies have demonstrated a strong association between ER inactivation and abnormal spermatogenesis, the specific role of ER gene mutations or polymorphisms in male infertility is still novel.

Any alteration in the genes involved in androgen-estrogen action or metabolism may disturb the androgen-estrogen balance. It is well known that estrogenic activity is mediated by at least two functional isoforms of the ER, ER $\alpha$ and ER $\beta{ }^{9,10}$ Previous investigations have proven that mutations of the ER (ER $\alpha$ knockout) in male mice leads to reduced mating frequency, lower sperm counts, and decreased sperm motility and fertilization ability. ${ }^{3,5}$ Other studies have identified two silent polymorphisms in the human $\mathrm{ER} \alpha$, which may be associated with both male and female infertility. ER $\alpha$ PvuII polymorphism (rs2234693) in women was found to affect pregnancy rates following in vitro fertilization (IVF) cycles, ${ }^{11,12}$ whereas XbaI polymorphism (rs9340799) was associated with either azoospermia or idiopathic severe oligospermia in men. ${ }^{13}$ Other ER $\alpha$ mutations may interfere with human spermatogenesis. ${ }^{14,15} \mathrm{ER} \alpha$ is known to be strongly expressed in the epididymis, efferent ductules and Leydig cells, whereas ER $\beta$ is predominantly expressed in germ cells, particularly in the primary spermatocytes and round spermatids of the human testis. ${ }^{16-19}$ These data suggest that ER $\beta$ may also play an important role in male infertility. Another investigation suggested that the RsaI polymorphism in ER $\beta$ was related to human spermatogenesis; the phenotype of testicular dysgenesis syndrome seems to be partly determined by the genotype of ER $\beta .^{20}$ In addition, the roles of genetic variants of $E R \beta$, with respect to Chinese infertile men and their clinical outcomes from IVF cycles, remain unknown.

Noticeably, the male-infertility rate has significantly increased in our reproductive center over the past decade, as well as in other countries. ${ }^{2,21}$ It is known that oligozoospermia, asthenozoospermia, teratozoospermia and azoospermia are the main causes of male infertility, accounting for about $30 \%$ of cases. Assisted reproduction technology, particularly the intracytoplasmic sperm injection (ICSI) technique, has been widely used for the treatment of male infertility, resulting in a significant increase in success rates. However, there were some cases with unexplained fertilization failure and early embryonic developmental arrest, which has traditionally been attributed to oocyte 
quality. Moreover, previous studies ${ }^{3,5}$ have indicated that male ER $\alpha$ knockout mice possess lower sperm counts and decreased sperm motility and fertilization ability. Accordingly, the aim of this study was to evaluate the relationship between the ER $\beta$ RsaI polymorphism in men, and the rates of fertilization and embryonic development in couples who underwent IVF or ICSI treatment.

\section{PATIENTS AND METHODS}

\section{Study population}

This study recruited 865 Chinese infertile couples undergoing IVF or ICSI cycles in Peking University Third Hospital Reproductive Center from 1 January to 31 October 2008; the patient population consisted of 374 couples undergoing conventional IVF cycles using ejaculated sperm, 294 couples undergoing ICSI cycles also using ejaculated sperm and 197 couples undergoing ICSI cycles using surgically retrieved sperm. Surgically retrieved sperm qualified as either a testicular sperm extraction or microsurgical epididymal sperm aspiration. Men with Klinefelter syndrome, Y-chromosome microdeletions, iatrogen infertility, hypogonadotrophic hypogonadism, karyotype anomalies, or other known genetic causes of infertility were excluded from this study. Women older than 43 years, or with premature ovarian failure, karyotype anomalies, other known genetic causes of infertility, known oocyte maturation arrest (previous cycles), or with poor ovarian response (with $\leqslant 3$ mature oocytes), were also excluded. In addition, no native Chinese patients were excluded. This study was approved by the Ethics Committees of the Hospital and all couples signed informed clinical consents.

\section{Genotyping}

Venous blood was collected in EDTA from all male patients. Genomic DNA was isolated using a salting-out procedure. RsaI genotypes were determined with the polymerase chain reaction (PCR)-restriction fragment length polymorphism method. The primers designed for this analysis were: 5'-ACTTGCCATTCTGTCTCTACA-3' (forward primer) and 5'-CACAGGACCCTGAATCCT-3' (reverse primer); the wild type generated a 409-bp fragment. PCR was run according to the procedure described by Aschim et al. ${ }^{20}$ (PCR regents were purchased from Tiangen Biotech Co., Ltd, Beijing, China).

After generation, PCR products were digested with RsaI restriction endonuclease (JingKeHongDa Biotechnology Co., Ltd, Beijing, Fermentas China) at $37^{\circ} \mathrm{C}$, overnight. The DNA fragments were visualized on $2 \%$ agarose gel using ethidium bromide staining. For RsaI polymorphism, a $\mathrm{G}$ to A nucleotide exchange at nucleotide 1082 in exon 5 of ER $\beta$ (GenBank accession no. AB006590) created an additional restriction site for RsaI endonuclease. As such, RsaI digestion producing only one band of $409 \mathrm{bp}$ classified the individual as possessing the homozygous wild-type GG genotype; if two bands of 110 and $299 \mathrm{bp}$ were visualized, this indicated the homozygous polymorphic AA genotype; finally, when three bands (110,299 and $409 \mathrm{bp}$ ) were present, those individuals were identified as heterozygous AG carriers.

\section{Follow-up fertilization results}

For all aforementioned infertile couples, clinical outcomes of IVF or ICSI treatment were tracked. Normal fertilization was confirmed by observing two pronuclear forms, 18-19 h after IVF insemination or ICSI. Total normal fertilization rates (per group) were calculated as the total number of zygotes with two pronuclear, divided by the total number of oocytes in conventional IVF cycles and metaphase II oocytes in ICSI cycles. The average normal fertilization rate was determined by calculating this rate for each cycle separately and averaging these values. High-quality embryo rates were assessed on day 3 as those embryos possessing $5-10$ equal-sized blastomeres, with $\leqslant 20 \%$ fragmentation. Mean high-quality embryo rates were determined by calculating this rate for each cycle separately, then averaging these values. Finally, the total and mean fertilization rates, and the total and mean of high-quality embryo rates were compared between different groups.

\section{Statistical analysis}

Statistical analysis was performed using the Statistical Package for the Social Sciences software 13.0 (SPSS 13.0). One-way ANOVA, chisquare testing (Pearson's chi-square) and two independent sample tests (Mann-Whitney U) were used for the statistical analysis. A $P$ value $<0.05$ was considered statistically significant.

\section{RESULTS}

\section{Distribution of the RsaI genotypes GG, AG and AA in specified} groups

As shown in Figure 1, genotypes were determined by digested PCR products. Simply, after being digested with RsaI restriction endonuclease, samples with one band of 409 bp were classified as possessing the homozygous wild-type GG genotype, samples with two bands of 110 and 299 bp were indicated the homozygous polymorphic AA genotype, and those with three bands (110, 299 and 409 bp) were identified as heterozygous AG carriers. At the same time, the genotypes on spermatozoa were also be defined, and no any difference was found between spermatozoa and genomes.

By calculating the results of PCR-restriction fragment length polymorphism, the frequency of the homozygous GG, heterozygous AG

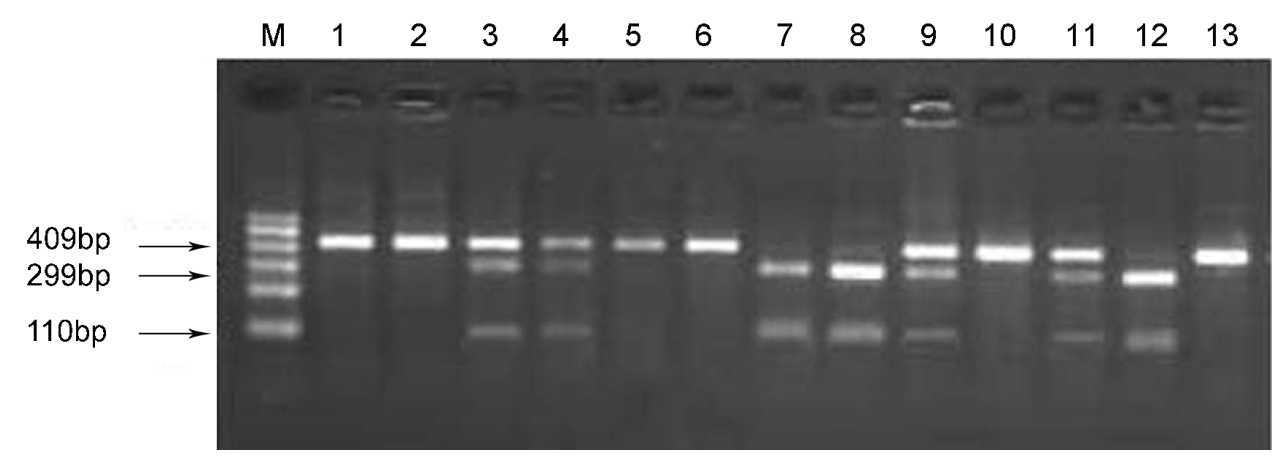

Figure 1 PCR-RFLP results. M: marker, 100-600 bp; 1-13: different samples. Wild-type GG genotype with one band of 409 bp, as in samples 1, 2, 5, 6, 10 and 13; homozygous polymorphic AA with two bands, 110 and 299 bp, as in samples 7, 8 and 12; heterozygous AG carriers with three bands, 110 , 299 and 409 bp, as in samples 3, 4, 9 and 11. PCR-RFLP, polymerase chain reaction (PCR)-restriction fragment length polymorphism. 
and homozygous AA genotype was 52.4\% (196/374), 39.0\% (146/374) and $8.6 \%(32 / 374)$, respectively, in the conventional IVF group, whereas the frequencies were $55.1 \%(162 / 294), 37.8 \%(111 / 294)$ and $7.1 \%(21 / 294)$ in the ejaculated ICSI group, and $46.7 \%(92 / 197)$, $41.1 \%(81 / 197)$ and $12.2 \%(24 / 197)$ in the surgically retrieved ICSI group, respectively.

\section{Association of RsaI polymorphism with fertilization results}

The roles of ER $\beta$ RsaI polymorphism contributing to sperm's fertilization ability and fertilization rates among different genotype subgroups were compared in this study. Table 1 showed patient demographics, along with their lab data. There were no differences among the different genotype groups with respect to patient age, partner age, average number of oocytes retrieved per cycle, average number of mature oocytes, overall fertilization rates and mean fertilization rate per cycle. In addition, although no significant differences were found in the overall rate of high-quality embryos among groups, decreasing trends could be observed between GG and AA genotypes for each group. There was also a statistically significant difference in the mean high-quality embryo rate between GG or AG, and AA genotypes in the ICSI group with ejaculated sperm $(76.1 \%$ versus $56.9 \%$, GG versus $\mathrm{AA}, P<0.01 ; 74.6 \%$ versus $56.9 \%$, AG versus AA, $P<0.01$, respectively). Furthermore, when comparing the IVF and ICSI with surgically retrieved sperm groups, there were obvious diminishing trends observed between GG and AA genotypes, although this did not reach a statistical difference.

To further determine the role of ER $\beta$ RsaI polymorphism in early embryonic development, the proportion of cycles with a satisfactory high-quality embryo rate (i.e. more than $50 \%, 60 \%$ and $80 \%$, for every genotype in each group, respectively) was calculated. Table 2 demonstrates that the proportion of cycles achieving a satisfactory highquality embryo rate in the GG genotype was obviously higher than that in AA genotypes in all ICSI and surgically retrieved cases $(P<0.05)$. In the conventional IVF group, a statistical difference in the proportion of cycles with high-quality embryos more than $50 \%$ was only determined between the GG and AA genotypes $(P=0.021)$.

\section{DISCUSSION}

In part, male infertility is likely the result of deletions and/or mutations in one or more of the myriad of genes involved in spermatogenesis. ${ }^{22}$ Through the knockout mouse model, more than 300 genes required for the normal spermatogenesis have been identified; ${ }^{23}$ even more have been proposed for the human male. These genes are defined as candidate genes for infertility. In recent years, the important role played by the ER in male reproduction has been elucidated in both animal models ${ }^{3}$ and humans, specifically in humans bearing mutations of the $\mathrm{ER} \alpha{ }^{24}$ and aromatase genes. ${ }^{25-27}$ Consequently, the ER and aromatase genes became candidates as infertility genes in the humans. The analysis of polymorphisms in candidate infertility genes represents an exciting frontier in the genetics of male infertility.

The human testes, particularly spermatogenic cells, contain an increased concentration of $\mathrm{ER} \beta{ }^{28,29}$ suggesting that $\mathrm{ER} \beta$ plays an important role during the regulation of spermatogenesis and spermiogenesis. ${ }^{30}$ Previous work demonstrated that the heterozygous ER $\beta$ RsaI AG genotype was associated with an approximately $20 \%$ reduction in luteinizing hormone concentration, compared to the wild-type ER $\beta$ RsaI GG genotype in both normospermic and infertile men. ${ }^{20}$ Investigations have suggested that the ER mutation leads to decreased sperm motility and fertilization ability. ${ }^{31}$ However, no report concerning the role of ER $\beta$ RsaI polymorphism in sperm fertilization and early embryonic development could be found.

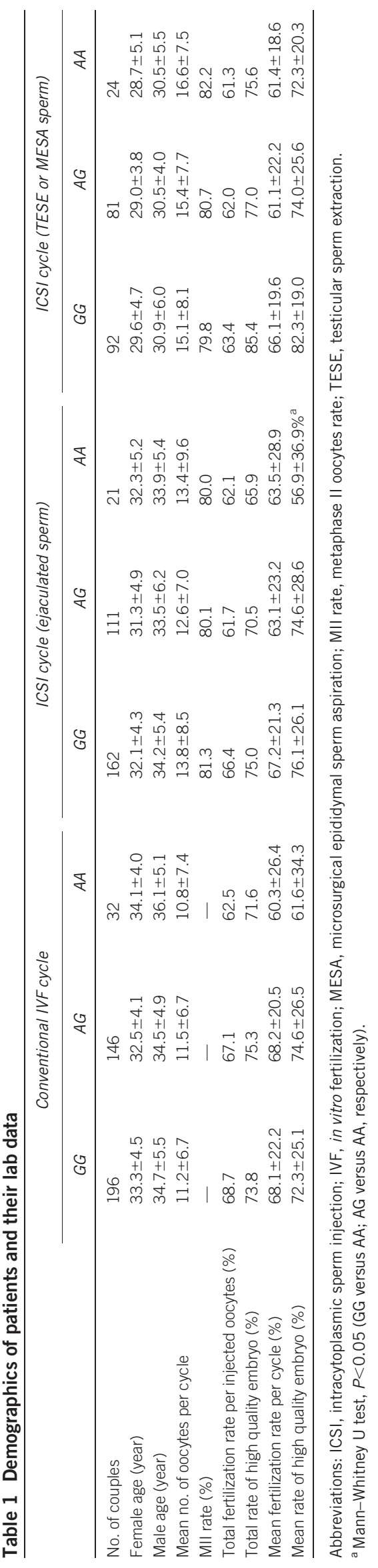


Table 2 The proportion of cycles with satisfied high quality embryo rate in different groups

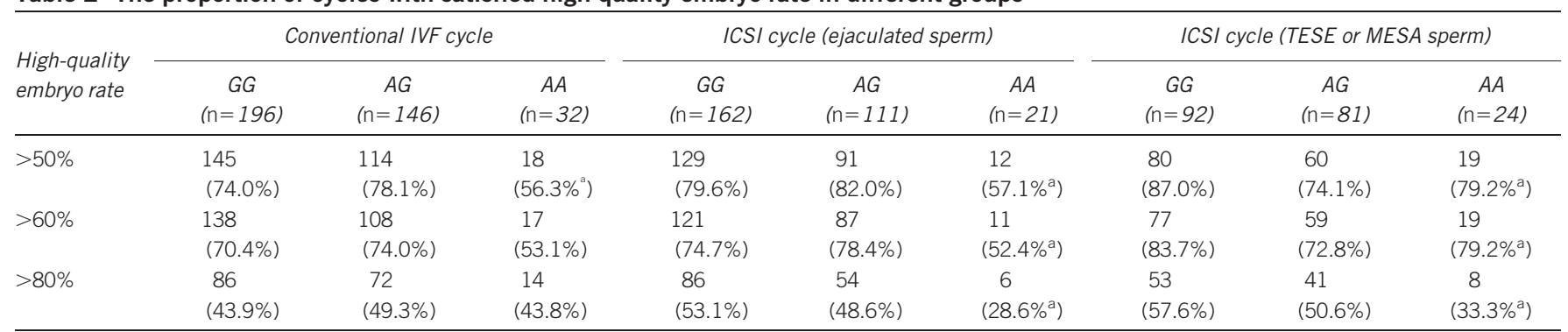

Abbreciations: ICSI, intracytoplasmic sperm injection; IVF, in vitro fertilization; MESA: microsurgical epididymal sperm aspiration; TESE, testicular sperm extraction.

${ }^{a}$ Chi-square tests, $P<0.05$ (AA versus GG in each group).

The present study was undertaken to determine the relationship between the ER $\beta$ RsaI polymorphism and sperm's fertilization ability and contribution to early embryonic development in conventional IVF and ICSI cycles. Physiologically, the mature sperm is a kind of haploid cell; as such, homozygous RsaI AA/GG patients must have a copy of the RsaI A/G genotype in all spermatozoa (respectively), and patients with the heterozygous RsaI AG genotype can produce spermatozoa with either the ER $\beta$ RsaI A genotype or the ER $\beta$ RsaI G genotype. In effect, the fertilization rate and early embryonic development between RsaI GG and AA genotypes was compared. The results showed that spermatozoa with the RsaI A genotype would likely possess decreased fertilization ability, and consequently have a negative influence on early embryonic development in vitro. Furthermore, this study suggested that the developmental potential might be possibly decreased in these embryos originated from spermatozoa along with ER $\beta$ RsaI A gene. However, mechanisms which decrease early embryonic development in vitro remain unknown. In addition, it was proved that ER $\beta$ protein was strongly expressed in mature sperm. So, we hypothesized that spermatozoa possessing ER $\beta$ RsaI A genotype could have reduced ER $\beta$ activity, thus leading to decreased early embryonic developmental potential. Unfortunately, these data could not strongly prove this hypothesis.

In addition, we also investigated implantation rates and the pregnancy outcomes in these patients after all couples were divided into three groups based solely upon their genotype. The results showed significant differences among the three groups. The AA genotype had a significantly higher early miscarriage rate $(27.5 \%)$ than did the other two groups (Pearson's chi-square value $=20.259$, degree of freedom $=2$ and $P=0.000$ ) (data not show). However, up to now, it was believed that early embryonic development in mammals is mainly dependent upon the maternal RNA and proteins within the oocyte, which had accumulated during oocyte growth and maturation; the onset of transition from maternal to embryonic regulation, referred to as 'embryonic genome activation', is initiated later during development at various preimplantation stages, varying by species. ${ }^{32-34}$ Furthermore, Rambags demonstrated that ER $\beta$ mRNA was expressed in 10- and 14-day embryos, but not in day 7 conceptuses after ovulation in the horse. ${ }^{35}$ This evidence may indicate that reproductive steroids influence embryonic development directly. Study on human fetal development suggests that the actions of estrogens are predominantly mediated through ER $\beta$, but not ER $\alpha \cdot{ }^{31,36}$ As such, patients with the homozygous ER $\beta$ RsaI AA genotype demonstrate reduced ER $\beta$ activity, leading to reduced estrogen sensitivity and may be a possible reason for the elevated pregnancy loss rate. However, because these outcomes are easily affected by maternal factors, including uterine malformation, pelvic inflammation, endometrium and so on, we did not show these data in this paper.
In summary, the present study demonstrates an association between the RsaI genotype of the ER $\beta$ gene and sperm fertilization and early embryonic development. The ER $\beta$ RsaI A genotype in sperm may effectively decrease early embryonic developmental potential. Unfortunately, the influence of the ER $\beta$ RsaI genotype from the female partner does not appear to be straight forward and could not be removed from the equation; this served as the limiting factor for this study and may be a potential focal point for future investigations.

\section{AUTHOR CONTRIBUTIONS}

QFZ, HLF, and JQ designed this study. PL recruited cases for this study and analyzed results. LZ collected samples and extracted genomic DNA. QFZ performed most of the experiments, analyzed results and wrote the manuscript. HLF and JQ revised the manuscript. LL and JY analyzed results. All authors discussed results and edited the manuscript.

\section{COMPETING FINANCIAL INTERESTS}

The authors declare no competing financial interests.

\section{ACKNOWLEDGMENTS}

We appreciate Jingqiao Lv for kind assistance in data analyses. Appreciation is extended to Mr Dennis E. Marchesi for his critical review and comments. This work was supported by national basic research program of China (973 Program No. 2007ZB948102).

1 O'Donnell L, Robertson KM, Jones ME, Simpson ER. Estrogen and spermatogenesis. Endocr Rev 2001; 22: 289-318.

2 Auger J, Kunstmann JM, Czyglik F, Jouannet P. Decline in semen quality among fertile men in Paris during the past 20 years. N Engl J Med 1995; 332: 281-5.

3 Eddy EM, Washburn TF, Bunch DO, Goulding EH, Gladen BC et al. Targeted disruption of the estrogen receptor gene in male mice causes alteration of spermatogenesis and infertility. Endocrinology 1996; 137: 4796-805.

4 Nakazumi H, Sasano H, Maehara I, Ozaki M, Tezuka F et al. Estrogen metabolism and impaired spermatogenesis in germ cell tumors of the testis. J Clin Endocrinol Metab 1996; 81: 1289-95.

5 Hess RA, Bunick D, Lee KH, Bahr J, Taylor JA et al. A role for oestrogens in the male reproductive system. Nature 1997; 390: 509-12.

6 Carreau S, Delalande C, Galeraud-Denis I. Mammalian sperm quality and aromatase expression. Microsc Res Tech 2009; 72: 552-7.

7 Carreau S, Lambard S, Delalande C, Denis-Galeraud I, Bilinska B et al. Aromatase expression and role of estrogens in male gonad: a review. Reprod Biol Endocrinol 2003; $1: 35$.

8 Rochira V, Granata AR, Madeo B, Zirilli L, Rossi G et al. Estrogens in males: what have we learned in the last 10 years? Asian J Androl 2005; 7: 3-20.

9 Gruber CJ, Tschugguel W, Schneeberger C, Huber JC. Production and actions of estrogens. N Engl J Med 2002; 346: 340-52.

10 Nilsson S, Makela S, Treuter E, Tujague M, Thomsen J et al. Mechanisms of estrogen action. Physiol Rev 2001; 81: 1535-65.

11 Sundarrajan C, Liao W, Roy AC, Ng SC. Association of oestrogen receptor gene polymorphisms with outcome of ovarian stimulation in patients undergoing IVF. $\mathrm{Mol}$ Hum Reprod 1999; 5: 797-802. 
12 Georgiou I, Konstantelli M, Syrrou M, Messinis IE, Lolis DE. Oestrogen receptor gene polymorphisms and ovarian stimulation for in-vitro fertilization. Hum Reprod 1997; 12: $1430-3$

13 Kukuvitis A, Georgiou I, Bouba I, Tsirka A, Giannouli CH et al. Association of oestrogen receptor alpha polymorphisms and androgen receptor CAG trinucleotide repeats with male infertility: a study in 109 Greek infertile men. Int J Androl 2002; 25: 149-52.

14 Suzuki Y, Sasagawa I, Itoh K, Ashida J, Muroya K et al. Estrogen receptor alpha gene polymorphism is associated with idiopathic azoospermia. Fertil Steril 2002; 78: 1341-3.

15 Guarducci E, Nuti F, Becherini L, Rotondi M, Balercia G et al. Estrogen receptor alpha promoter polymorphism: stronger estrogen action is coupled with lower sperm count. Hum Reprod 2006; 21: 994-1001.

16 Enmark E, Pelto-Huikko M, Grandien K, Lagercrantz S, Lagercrantz J et al. Human estrogen receptor beta-gene structure, chromosomal localization, and expression pattern. J Clin Endocrinol Metab 1997; 82: 4258-65.

17 Pelletier G, El-Alfy M. Immunocytochemical localization of estrogen receptors alpha and beta in the human reproductive organs. J Clin Endocrinol Metab 2000; 85: 4835-40.

18 Saunders PT, Sharpe RM, Williams K, Macpherson S, Urquart H et al. Differential expression of oestrogen receptor alpha and beta proteins in the testes and male reproductive system of human and non-human primates. Mol Hum Reprod 2001; 7: 227-36.

19 Saunders PT, Millar MR, Macpherson S, Irvine DS, Groome NP et al. ERbetal and the ERbeta2 splice variant (ERbetacx/beta2) are expressed in distinct cell populations in the adult human testis. J Clin Endocrinol Metab 2002; 87: 2706-15.

20 Aschim EL, Giwercman A, Stahl O, Eberhard J, Cwikiel M et al. The Rsal polymorphism in the estrogen receptor-beta gene is associated with male infertility. J Clin Endocrinol Metab 2005; 90: 5343-8.

21 Jensen TK, Carlsen E, Jorgensen N, Berthelsen JG, Keiding N et al. Poor semen quality may contribute to recent decline in fertility rates. Hum Reprod 2002; 17: 1437-40.

22 Poongothai J, Gopenath TS, Manonayaki S. Genetics of human male infertility. Singapore Med J 2009; 50: 336-47.

23 Escalier D. Animal models: candidate genes for human male infertility. Gynecol Obstet Fertil 2006; 34: 827-30. French.

24 Herynk MH, Fuqua SA. Estrogen receptor mutations in human disease. Endocr Rev 2004; 25: 869-98.
25 Morishima A, Grumbach MM, Simpson ER, Fisher C, Qin K. Aromatase deficiency in male and female siblings caused by a novel mutation and the physiological role of estrogens. J Clin Endocrinol Metab 1995; 80: 3689-98.

26 Deladoey J, Fluck C, Bex M, Yoshimura N, Harada N et al. Aromatase deficiency caused by a novel P450arom gene mutation: impact of absent estrogen production on serum gonadotropin concentration in a boy. J Clin Endocrinol Metab 1999; 84 4050-4.

27 Maffei L, Murata Y, Rochira V, Tubert G, Aranda C et al. Dysmetabolic syndrome in a man with a novel mutation of the aromatase gene: effects of testosterone, alendronate and estradiol treatment. J Clin Endocrinol Metab 2004; 89: 61-70.

28 Gruber CJ, Tschugguel W, Schneeberger C, Huber JC. Production and actions of estrogens. N Engl J Med 2002; 346: 340-52.

29 Makinen S, Makela S, Weihua Z, Warner M, Rosenlund B et al. Localization of oestrogen receptors alpha and beta in human testis. Mol Hum Reprod 2001; 7 497-503.

30 Carreau S, Silandre D, Bourguiba S, Hamden K, Said L et al. Estrogens and male reproduction: a new concept. Braz J Med Biol Res 2007; 40: 761-8.

31 Su MT, Chen CH, Kuo PH, Hsu CC, Lee IW et al. Polymorphisms of estrogen-related genes jointly confer susceptibility to human spermatogenic defect. Fertil Steril 2010, 93: 141-9.

32 Jeanblanc M, Salvaing J, Mason K, Debey P, Beaujean N. Embryonic genome activation. Gynecol Obstet Fertil 2008; 36: 1126-32. French.

33 Aoki F, Worrad DM, Schultz RM. Regulation of transcriptional activity during the first and second cell cycles in the preimplantation mouse embryo. Dev Biol 1997; 181: 296-307.

34 Leandri RD, Archilla C, Bui LC, Peynot N, Liu Z et al. Revealing the dynamics of gene expression during embryonic genome activation and first differentiation in the rabbit embryo with a dedicated array screening. Physiol Genomics 2009; 36: 98-113.

35 Rambags BP, van Tol HT, van den Eng MM, Colenbrander B, Stout TA. Expression of progesterone and oestrogen receptors by early intrauterine equine conceptuses. Theriogenology 2008; 69: 366-75.

36 Takeyama J, Suzuki T, Inoue S, Kaneko C, Nagura $\mathrm{H}$ et al. Expression and cellular localization of estrogen receptors alpha and beta in the human fetus. J Clin Endocrinol Metab 2001; 86: 2258-62. 